\title{
Evaluación del crecimiento de cuatro especies del género Bacillus sp., primer paso para entender su efecto biocontrolador sobre Fusarium sp.
}

\author{
Evaluation of growth of four species of the genus Bacillus sp., \\ the first step to understand their biocontrol effect on Fusarium sp.
}

Estefania Castañeda Alvarez ${ }^{1}$ Ligia Consuelo Sánchez²

\section{Resumen}

Objetivo. Evaluar las condiciones de crecimiento de cuatro especies de Bacillus sp. nativas a escala de $10 \mathrm{ml}$ en Medio Mínimo de Sales (MMS) como primer paso para entender su acción biocontroladora contra Fusarium sp. Métodos. El procedimiento para evaluar el crecimiento de los aislamientos UCMC-TB1, UCMC-TB2, UCMC-TB3 y UCMC-TB4 se realizó utilizando espectrofotometría y recuento directo en placa y pruebas de antagonismo dual en placa para evaluar el efecto controlador contra Fusarium sp. Resultados. Se confirmó la identificación por pruebas bioquímicas de los cuatro aislamientos: Bacillus licheniformis, Bacillus subtilis, Bacillus pumilus y Bacillus cereus; todas las cepas presentaron antagonismo in vitro. El Bacillus subtilis fue la especie que demostró mayor capacidad antagónica (79,73\%PICR) y las características más destacadas de esta cepa fueron su velocidad de crecimiento. El género Bacillus es uno de los más reportados para usar en el control biológico de hongos como Fusarium sp. el cual ataca un gran número de cultivos de interés económico para el sector agrícola en Colombia.

Palabras clave: Control Biológico, Antibiosis, curva de crecimiento, Bacillus subtilis, Fusarium sp.

\section{Abstract}

Objetive. Evaluate the conditions of growth of four species of native Bacillus sp. on the scale of in minimal medium $10 \mathrm{ml}$ Sales (MMS) as a first step to understand their biocontrol action against Fusarium sp. Methods. The procedure for evaluating the growth of UCMC-TB1, UCMC-TB2, UCMC-TB3 and TB4 UCMC-isolates was performed using spectrophotometry and direct plate count and dual antagonism tests to evaluate the effect against Fusarium sp. Results. Identification by biochemical tests of the four isolates were confirmed: Bacillus licheniformis, Bacillus subtilis, Bacillus pumilus and Bacillus cereus; all showed antagonism in vitro. Bacillus subtilis was the species that showed increased antagonistic capacity (79.73\% PICR) and the main features of this strain were the speed of growth and death. The genus Bacillus is one of the most reported for use in the biological control of fungi such as Fusarium sp. It is attacking a large number of crops of economic interest to the agricultural sector in Colombia.

Keywords: Biological Control, Antibiosis, growth curve, Bacillus subtilis, Fusarium sp.

1. Profesional-Joven Investigador grupo CEPARIUM. Universidad Colegio Mayor de Cundinamarca, Bogotá, Colombia. orcid.org/0000-0001-6711-8861

2. Docente Investigador, Director grupo CEPARIUM Universidad Colegio Mayor de Cundinamarca, Bogotá, Colombia. orcid.org/0000-0001-7796-1326

Correspondencia: estefania128@gmail.com

Fecha de recepción: Junio 27 de 2016 - Fecha de aprobación: Octubre 18 de 2016 


\section{Introducción}

En Colombia, diversos productos agrícolas de consumo nacional, se proyectan como una alternativa potencial e innovadora en el mercado internacional, dada la heterogeneidad biológica, la dispersión geográfica y las condiciones agroecológicas que permiten el óptimo desarrollo del cultivo, como por ejemplo, las plantas aromáticas y hortalizas que vienen considerándose una oportunidad empresarial para medianosy pequeños productores locales $(1,2)$ y que de acuerdo con el Ministerio de Agricultura y Desarrollo Rural, aumentar el número de hectáreas sembradas en el país, poner en práctica sistemas de cultivo con estándares de calidad y cubrir la demanda global del producto son una necesidad próxima (2).

Esto significa que es necesario trabajar en la trazabilidad de los productos y para ello, deben estar detallados y controlados todos los aspectos del cultivo dentro de los parámetros de inocuidad y fitosanidad. El fusarium oxysporum representa un complejo de especies asociadas a importantes enfermedades en plantas y humanos y toxicidad microbiana (3); su patogenicidad en plantas está mediada por la ejecución de diversos mecanismos que incluyen la producción de micotoxinas, colonización en el interior de la planta, afección del sistema vascular y obstrucción del flujo de agua, que lo convierten en el principal agente causal de la denominada "marchitez vascular" y "pudrición de la raíz" $(4,5)$.

Entre las principales especies de Fusarium se encuentran: Fusarium oxysporum f. sp lycopersici (Fol) (Marchitez del tomate) (4, 6), Fusarium oxysporum f. sp cubense (Foc) (Mal del banano en Panamá) (5); Fusarium oxysporum f. sp phaseoli (marchitez del fréjol); Fusarium oxysporum f.sp. pisi (marchitez de la alverja); Fusarium oxysporum f. sp. dianthi (marchitez del clavel); Fusarium oxysporum f.sp. chrysanthemi (marchitez del crisantemo), entre otras $(3,7)$.

La erradicación de estas enfermedades se ha realizado por mucho tiempo con agroquímicos y su uso indiscriminado ha inducido mecanismos de resistencia microbiana $(4,8)$, que junto con las consecuencias propias del calentamiento global, facilitan la proliferación de la enfermedad y hacen más difícil la intervención de las mismas. El control biológico aparece como una alternativa limpia (9) y ha sido definida por Baker y colaboradores como: "el conjunto de mecanismos de aprovechamiento de las reacciones metabólicas, bioquímicas, mecánicas y/o físicas de los microorganismos nativos específicos de un ambiente, capaces de ejercer articulada o individualmente la inhibición de un patógeno sin alterar el equilibrio ecológico" (10) e incluyen: la antibiosis, la competencia y la interacción directa con el patógeno sea por parasitismo, predación o inducción de resistencia (11-13).

El género Bacillus, perteneciente a la familia Bacillaceae, y sus especies más representativas: B. subtilis, B. brevis, B. cereus, B. pumilus, B. licheniformis y $B$. amyloliquefaciens ofrecen una importante alternativa como agentes de control biológico (BCAs) (14), gracias a su ubicuidad en el suelo, a la producción de esporas resistentes a la desecación, calor, irradiación UV y solventes orgánicos; por ser promotor de crecimiento en plantas (PGPR) (15); a su sistema de resistencia inducida (ISR), además de la producción de sustancias de tipo enzimático (Quitinasa, $\beta-1,3$ glucanasa, xilanasa) $(16,17)$ y antibiótico (Iturinas, surfactinas y fengicinas) (18, 19). En el caso de las Iturinas, estas se producen en períodos de tiempo específico a lo largo de la curva de crecimiento y actúan en la inhibición de la germinación del hongo micelial, afectan la permeabilidad de la membrana e inducen de la muerte del patógeno $(19,20)$.

Los metabolitos primarios, compuestos de bajo peso molecular que participan como productos intermediarios en las diversas rutas metabólicas, se sintetizan durante la fase exponencial, en tanto que los de tipo antibiótico o metabolitos secundarios, se producen en la fase estacionaria e intervienen en vías biosintéticas específicas del proceso celular como 
productos finales (21). Su producción requiere un incremento en la biomasa del microorganismo productor, condiciones nutricionales específicas y factores físico-químicos, como la temperatura y los $\mathrm{pH}$ definidos para cada especie (22-24).

Así como, otro tipo de condiciones de incubación (agitación, tiempo de incubación, aireación), tamaño y edad del inóculo inicial que definirán la adaptación del microorganismo y la producción de la biomolecula $(17,25)$.

Se reporta que el crecimiento del Bacillus subtilis, se encuentra condicionado por la cantidad de sustratos esenciales como fuentes de carbono y nitrógeno, cuando se limitan estos requerimientos nutricionales los bacilos se estresan y esporulan siendo definitivos como fuentes de carbono la glucosa, sacarosa, harina de maíz y almidón; fuentes de nitrógeno, la peptona, polvo de levadura, $\mathrm{NH}_{4} \mathrm{Cl},\left(\mathrm{NH}_{4}\right) \mathrm{SO}_{4}, \mathrm{NH}_{4} \mathrm{NO}_{3}, \mathrm{KNO}_{3}$, y $\mathrm{NaNO}_{3}$; y las sales minerales: $\mathrm{MgSO}_{4}, \mathrm{FeSO}$, $\mathrm{CaCO}_{3}, \mathrm{KH}_{2} \mathrm{PO}_{4}$, y $\mathrm{K}_{2} \mathrm{HPO}_{4}(26,27)$ Por lo anterior conocer la capacidad de crecimiento y el comportamiento de las especies de este género con respecto a las condiciones nutricionales y físicoquímicas, son la primera estrategia para seleccionar el microorganismo que pueda tener la mejor adaptación para un proceso tecnológico a escala.

El siguiente paso, es utilizar técnicas de biología molecular para caracterizar y confirmar la presencia de genes que codifican para antibióticos en el género Bacillus (28-30) y los promotores asociados para su producción, a partir de la biosíntesis por NPRS (Nonribosomal peptide synthetases) o PKS (Polyketide synthase) $(31,32)$.

En este estudio, se definieron las fases de la curva de crecimiento microbiano a pequeña escala de las cepas UCMC-TB1, UCMC- TB2, UCMCTB3 Y UCMC-TB4 en relación a la temperatura y se comprobó in vitro su capacidad antagónica contra Fusarium sp.

\section{Materiales y Métodos}

\section{Cepas bacterianas y hongo fitopatógeno}

Los aislamientos de cepas UCMC TB1, TB2, TB3 y TB4, provistas por el Cepario de la Universidad Colegio Mayor de Cundinamarca fueron obtenidas en trabajos anteriores de rizósfera de la planta ornamental Ornithogallum umbellatum y de plantas aromáticas de la Universidad Nacional de Colombia. Las cepas estaban conservadas a $-70^{\circ} \mathrm{C}$ en caldo BHI con glicerol al 10\%. Todos los aislamientos bacterianos fueron sembrados en medio caldo Infusión Cerebro Corazón (BHI) de Oxoid $^{\circledR}$. Se Incubaron a $37^{\circ} \mathrm{C}$ durante $24 \mathrm{~h}$ y posteriormente fueron sembrados en Agar Sangre BD ${ }^{\circledR}$ durante 24h, según protocolo descrito por Corrales y Sánchez (33) para verificar viabilidad y características macroscópicas compatibles con Bacilos.

El Fusarium sp. se sembró en Agar Papa Dextrosa (PDA de OXOID ${ }^{\circledR}$ ), durante 7 días a $25^{\circ} \mathrm{C}$.

\section{Medios de cultivo}

Para evaluar el comportamiento nutricional de todas las cepas bacterianas en estudio, se utilizó Medio Mínimo de Sales MMS: $1.2 \mathrm{~g} / \mathrm{L}\left(\mathrm{NH}_{4}\right)_{2} \mathrm{SO}_{4}$, $0.1 \mathrm{~g} / \mathrm{L} \mathrm{CaCl} \cdot 2 \mathrm{H}_{2} \mathrm{O}, 0.1 \mathrm{~g} / \mathrm{L} \mathrm{MgSO}_{4} \cdot 7 \mathrm{H}_{2} \mathrm{O}$, $0.01 \mathrm{~g} / \mathrm{L} \mathrm{FeSO}_{4} \cdot 7 \mathrm{H}_{2} \mathrm{O}, 0.2 \mathrm{~g} / \mathrm{L} \mathrm{K}_{2} \mathrm{HPO}_{4}$ y $0.1 \mathrm{~g} / \mathrm{L}$ $\mathrm{KH}_{2} \mathrm{PO}_{4}$, ajustado a $\mathrm{pH} 6,0$.

\section{Preparación de biomasa e inóculo inicial}

Se inoculó con asa estéril, calibrada $0,5 \mu \mathrm{m}$, cada uno de los microorganismos en $10 \mathrm{ml}$ de Caldo MMS respectivamente y se dejó en agitación constante en agitador orbital, durante $12 \mathrm{~h}$ a $180 \mathrm{rpm}$ a $37^{\circ} \mathrm{C}$. Posteriormente se centrifugó a $5000 \mathrm{rpm}$, durante $15 \min$ a $4^{\circ} \mathrm{C}$. Se descartó el sobrenadante y se resuspendieron las células concentradas en $100 \mu \mathrm{l}$ de solución salina al 1\%. Se homogenizó en vórtex y se ajustó a $1,5 \times 10^{8}$ células $/ \mathrm{ml}^{3}$. 


\section{Ensayo por espectrofotometría a $10 \mathrm{ml}$}

Cada cepa fue inoculada al 1\% en crioviales estériles que contenían $10 \mathrm{ml}$ del medio de cultivo SMS. Se incubaron aeróbicamente a $37^{\circ} \mathrm{C}$. Se hizo lectura espectrofotométrica contra blanco del medio de cultivo, a la longitud de Onda calibrada $(300 \mathrm{~nm})$ en intervalos de $1 \mathrm{~h}$ hasta completar 25 observaciones. Cada ensayo fue realizado por duplicado.

\section{Ensayo directo por recuento en placa}

Por cada hora se prepararon hasta 8 diluciones en solución salina al $1 \%$ del inóculo incubado. Se sembró $20 \mu \mathrm{l}$ de cada dilución por técnica de microgota en placa de Agar MMS (34). Cada dilución se sembró por duplicado y se incubó durante $24 \mathrm{~h}$. Las placas en las que crecieron entre 30 y 300 colonias, fueron seleccionadas y el número de colonias obtenido se multiplicó por el factor de corrección, 50, para completar el recuento a un mililitro y finalmente por el inverso de la dilución empleada. El recuento se reportó en $\mathrm{UFC} / \mathrm{ml}$.

\section{Pruebas de antagonismo}

Se evaluaron por triplicado 5 tratamientos (T), Tabla 1.

Tabla 1. Tratamientos evaluados en Prueba de Antagonismo dual

\begin{tabular}{cc}
\hline Ítem & Tratamiento \\
\hline $\mathrm{T} 1$ & Fusarium sp.+ UCMC-TB1 \\
$\mathrm{T} 2$ & Fusarium sp.+ UCMC-TB2 \\
$\mathrm{T} 3$ & Fusarium sp.+ UCMC-B3 \\
$\mathrm{T} 4$ & Fusarium sp. + UCMC-TB4 \\
$\mathrm{T} 5$ & Fusarium sp.+ AGUA \\
\hline
\end{tabular}

El Fusarium sp. se sembró en agar papa dextrosa 7 días previos a la prueba de antagonismo y las cepas bacterianas UCMC TB1, UCMC TB2, UCMC TB3 y UCMC TB4 con $12 \mathrm{~h}$ de anterioridad en caldo $\mathrm{MMS}$ a $37^{\circ} \mathrm{C}$.

Se utilizaron discos de $4 \mathrm{~mm}$ de diámetro por $2 \mathrm{~mm}$ de alto de la zona micelial del Fusarium sp. y se fijaron en dos extremos opuestos en placa de agar papa dextrosa (PDA). Posteriormente, se inoculó $20 \mu \mathrm{l}$ de cada tratamiento en línea recta central y equidistante a los discos del hongo sembrado. Se usó agua destilada estéril como control negativo. Se incubó a $25 \pm 1^{\circ} \mathrm{C}$ durante 12 días.

Posteriormente se halló el Porcentaje de Inhibición del Crecimiento Radial (PICR), mediante la lectura del diámetro de la zona radial del patógeno con regla de pie de Rey y se aplicó la ecuación de Ezziyyani y colaboradores (34).

Eq 1) $P I C R=(R 1-R 2) / R 1 \times 100$

Donde R1 es el radio del patógeno testigo y R2 es el radio del patógeno en enfrentamiento.

\section{Resultados}

\section{Fenotipificación de las cepas bacterianas}

El aislamiento en agar sangre, permitió evidenciar las características macroscópicas propias del genero Bacillus sp., Figura 1.

La coloración de Gram, evidenció bacilos Gram positivos. La identidad de las cepas, confirmadas por BBL- CRYSTAL ${ }^{\oplus}$, arrojaron como resultado para la Cepa UCMC-TB2: Bacillus subtilis, con porcentaje de homología del $98,1 \%$ para las cepas UCMC-TB1: Bacillus licheniformis, Cepa UCMC-TB3: Bacillus pumilus y Cepa UCMCTB4: Bacillus cereus con un 99,9\% de homología.

\section{Curva de Crecimiento por espectrofotometría}

Por medio de los ensayos espectrofotométricos, se observa que el crecimiento bacteriano de cada cepa fue diferente, figura 2. Se puede apreciar la fase Lag corta en especies como B. cereus y B. pumilus y mucho más larga en especies como $B$. licheniformis y $B$. subtilis, donde alcanza hasta 4 horas. La fase exponencial, demuestra la replicación acelerada de cada una de las cepas, entre un lapso no mayor a 5 horas posterior a la fase Lag. Además, se evidencia 

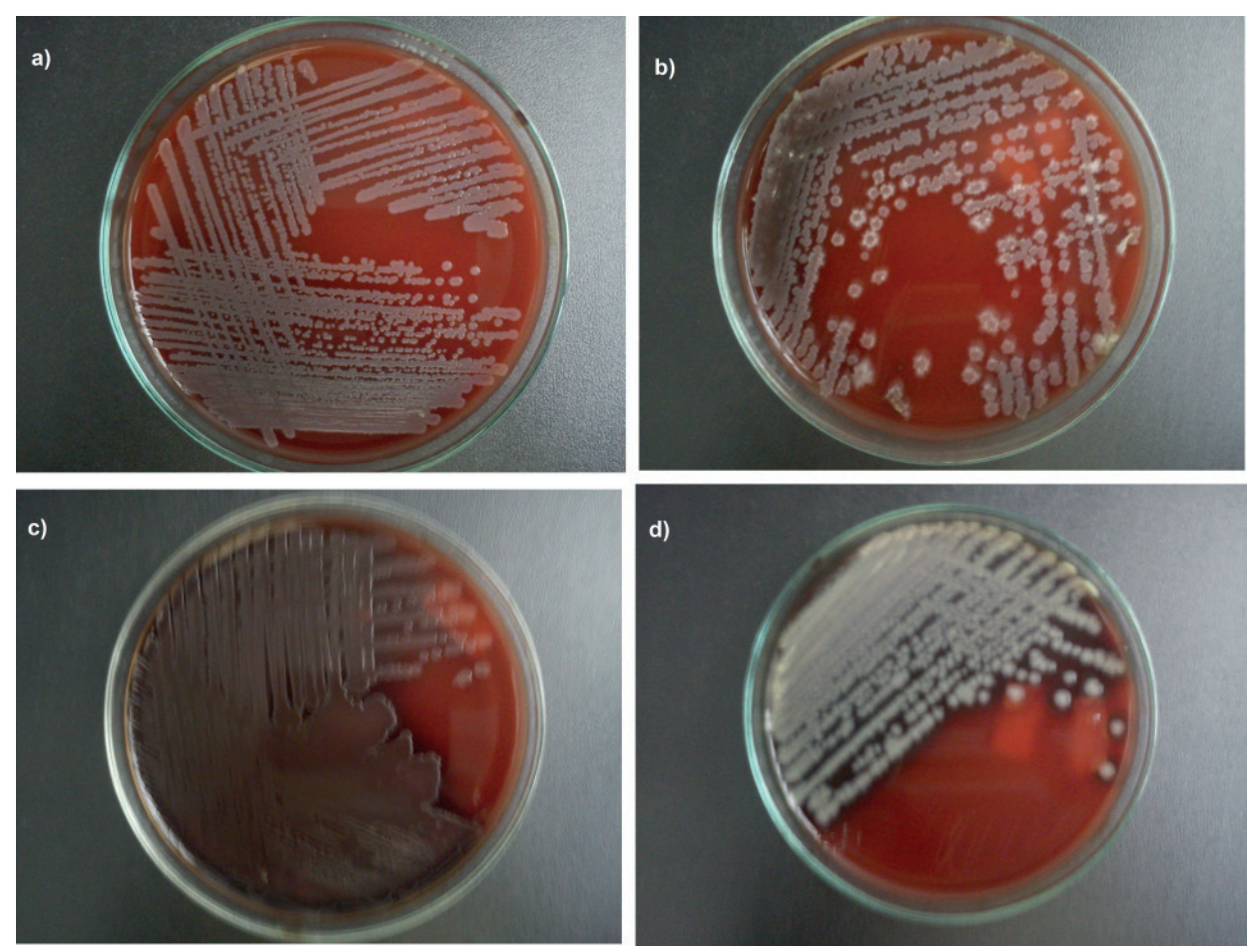

Figura 1. Cultivo de especies de Bacillus en Agar Sangre. a). B. licheniformis, b). B. subtilis, c). B. pumilus y d). B. cereus.
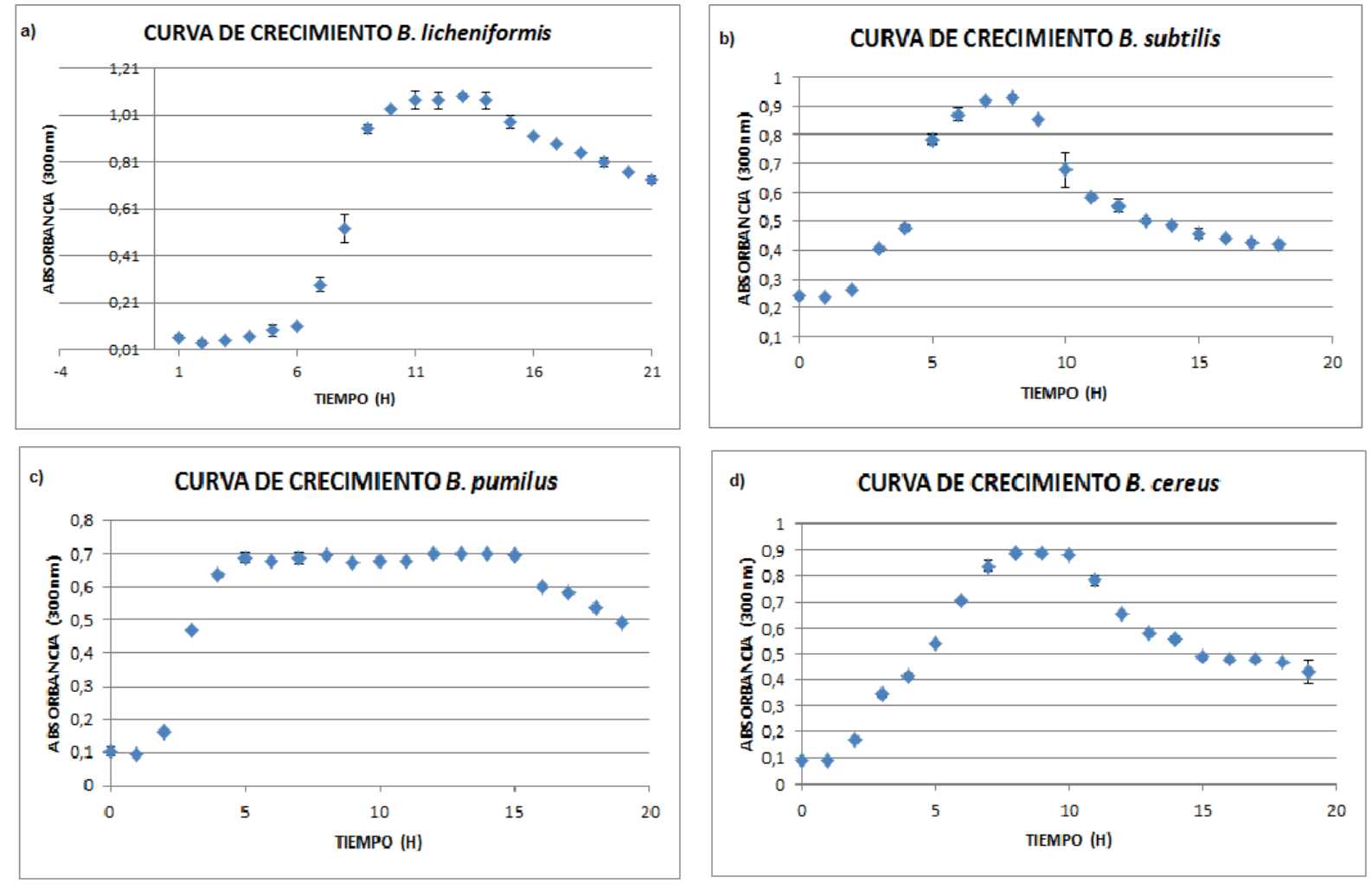

Figura 2. Curvas de crecimiento por espectrofotometría a $300 \mathrm{~nm}$. a) Bacillus licheniformis b) Bacillus subtilis c) Bacillus pumilus d) Bacillus cereus 
el aumento en UFC/mL durante ésta fase de crecimiento en comparación con el resto de la curva de crecimiento. Posterior a ello, aparece la fase de latencia y muerte, determinada por la disminución de nutrientes, factores esenciales para la respiración; aumento en la cantidad de otros metabolitos que pueden ser sustancias tóxicas y variación del $\mathrm{pH}$ hacia la acidez. El B. subtilis demuestra ser una de las especies con mayor velocidad de crecimiento y muerte de acuerdo con los datos que describe la gráfica de la curva, Figura2b; mientras que $B$. pumilus, marca una prolongada fase de latencia, Figura 2c. De igual forma el ensayo directo por recuento en placa evidencia el mismo comportamiento y confirma las células viables en cada fase de la curva, Figura 3.
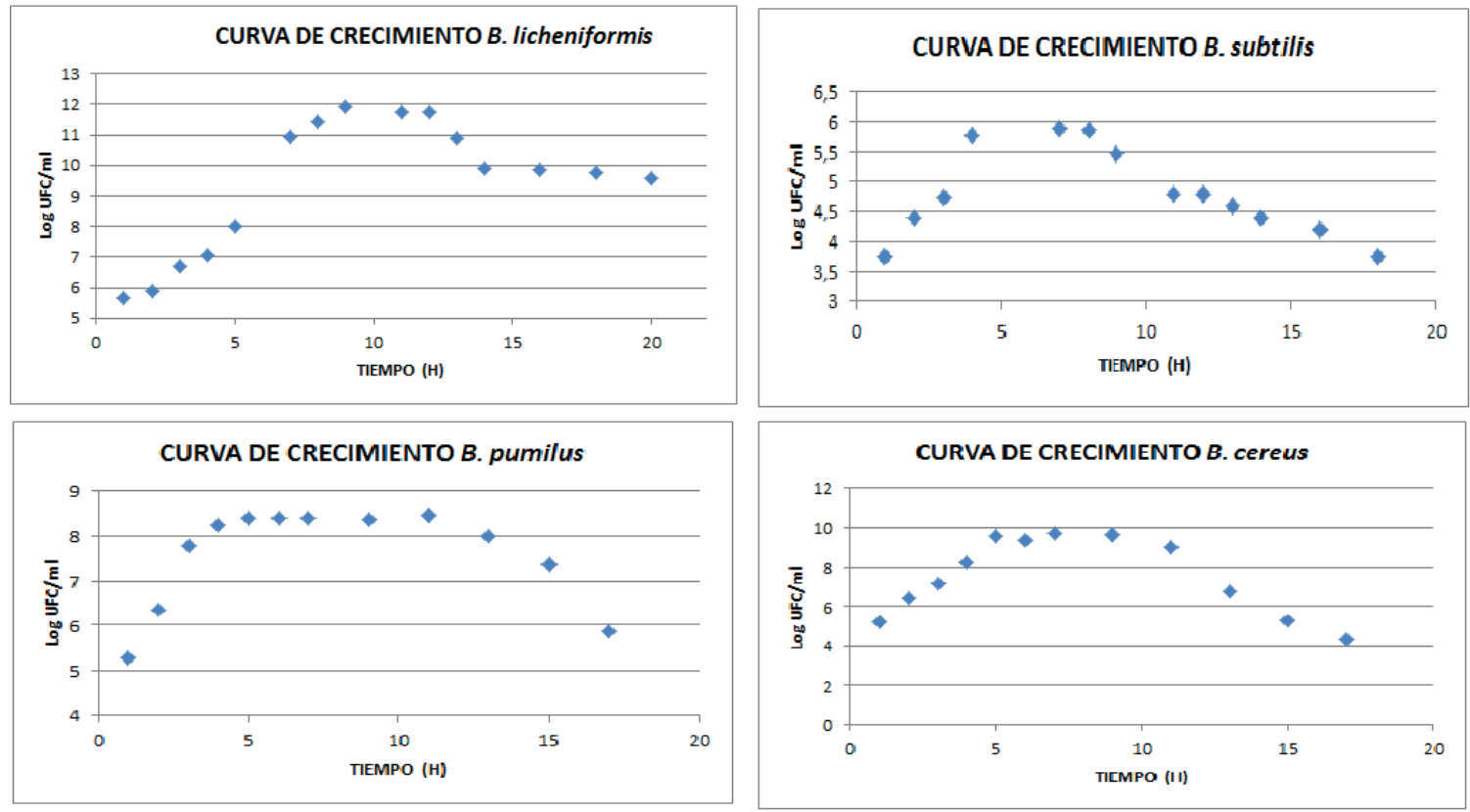

Figura 3. Curvas de crecimiento por ensayo directo de recuento en placa.

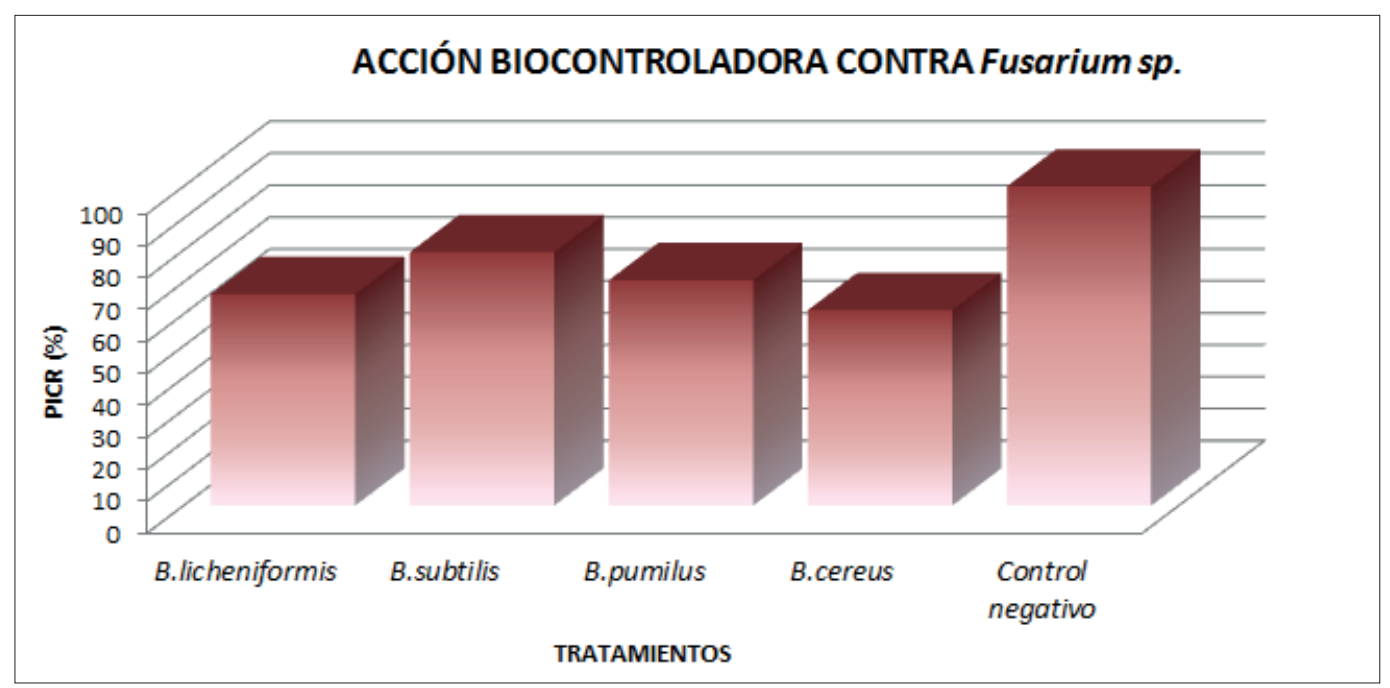

Figura 4. Porcentaje de Inhibición del crecimiento Radial -PICR- del patógeno. Lectura a los doce días de competencia dual entre los biocontroladores del género Bacillus y Fusarium sp. 


\section{Capacidad antagónica del Bacillus contra Fusarium sp.}

La inhibición del crecimiento de Fusarium sp.se observó en todos los tratamientos, posiblemente por la acción antagónica mediada por antibiosis, característico de éstas especies de biocontroladores.

En la Figura 4 se muestra el comportamiento de los cultivos duales con respecto a la reducción del crecimiento de Fusarium sp., observándose que a los doce días el T2, correspondiente a la cepa nativa de $B$. subtilis, fue la que exhibió el mayor PICR con un 79,37\%, figura 5, seguido por T3, donde se evaluó la cepa nativa de $B$. pumilus con un $70,6 \%$, B. licheniformis con un PICR de $66,2 \%$ y por último el $B$. cereus con $61,2 \%$ de Inhibición del Fusarium sp.

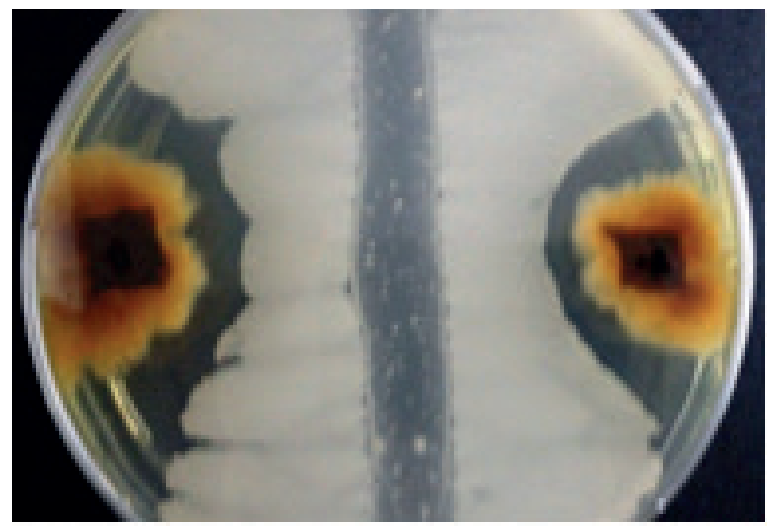

Figura 5. Prueba In vitro de Antagonismo B.subtilis y Fusarium sp.

\section{Discusión}

El crecimiento microbiano radica en un complejo número de reacciones equilibradas que determinan su metabolismo. Estas reacciones catabólicas o anabólicas están sujetas a variables ambientales que influyen en las condiciones y tasas de crecimiento celular (35). Su comprensión ha sido evaluada a partir de sistemas sencillos de fermentación, hasta amplios modelos en biorreactores en sistema líquido o sólido que permiten una combinación de variables que favorecen la obtención de metabolitos a partir de agentes microbianos en todo tipo de industria.
Definir y comprender la curva de crecimiento de especies del género Bacillus sp., bacilos Gram positivos, aerobios estrictos o anaerobios facultativos capaces de formar esporas, permite un acercamiento al modelo de cultivo para obtención de enzimas o antibióticos.

Durante la fase Lag o fase de adaptación, las células se ajustan a su nuevo ambiente, por lo cual su metabolismo aumenta la síntesis de productos intermediarios, ARN principalmente ribosómico para la producción de proteínas bacterianas y enzimas. Se puede observar que hay un aumento del volumen de cada organismo con un almacenamiento de agua para iniciar todo el proceso de síntesis bioquímica, pero no hay división de los mismos, ya que los niveles de ADN se mantienen constantes en esta etapa (21).

En la fase logarítmica, las bacterias se reproducen por fisión binaria a intervalos regulares, incrementando su número y su biomasa en forma exponencial. El intervalo de tiempo de replicación, conocido también como tiempo de generación, puede variar entre especies, como fue evidenciado a partir de las curvas de crecimiento obtenidas. En esta fase se obtiene el mayor recuento de individuos viables por hora. La tasa máxima de crecimiento, está limitada únicamente por la capacidad de las bacterias de procesar los nutrientes (21). Frecuentemente los medios de cultivo, incluyen macroelementos como el Nitrógeno $(\mathrm{N})$, Fósforo (P) y Potasio (K), la limitación de estos dos últimos inducen el desacoplamiento de procesos catabólicos y anabólicos que consecuentemente disminuyen el rendimiento de la biomasa, en tanto que limitar la disponibilidad de $\mathrm{N}$ tiene un efecto en la fisiología celular (35). El medio de cultivo mínimo de sales, MMS, utilizado para este ensayo, incluyó como principal sustrato la glucosa como fuente de carbono y el extracto de levadura como fuente de nitrógeno, además de iones de potasio que están reportadas por ser activadoras de varias enzimas y participar en la producción de proteínas. El ión magnesio, es utilizado como cofactor, ya que favorece la transferencia de grupos fosfatos, 
la activación y adecuado funcionamiento de los ribosomas, las membranas y los ácidos nucleicos al igual que el mantenimiento del $\mathrm{pH}$ para el metabolismo del género Bacillus sp. $(27,36)$.

El medio mínimo de sales, de acuerdo con Kapilan y Arasaratnam (37), al proporcionar elementos traza, aniones y cationes junto con moléculas complejas como la peptona y la glucosa permiten la prolongación de la fase exponencial y la producción de metabolitos. La glucosa es generalmente usada como un sustrato limitante de crecimiento, la peptona es una fuente de $\mathrm{C}$ y $\mathrm{N}$ en fermentaciones de Bacillus debido al crecimiento lento de las células en ausencia de estos componentes orgánicos (38).

Finalizada ésta etapa, la tasa de reproducción decrece hasta que el número de bacterias existentes es estacionario, lo que ocurre cuando la tasa de reproducción es igual a la tasa de mortalidad, observándose que la población se mantiene constante por un período de tiempo. En esta fase se consumen los nutrientes, se disminuyen los factores esenciales para la respiración, aumenta el número de sustancias tóxicas y varía el $\mathrm{pH}$ hacia la acidez $(21,38)$.

En la fase de muerte, el número de células bacterianas viables desciende, es el proceso inverso de la fase logarítmica, sin olvidar que de igual forma los microorganismos mueren en diferentes períodos ya que no todas se desarrollan al mismo tiempo.

Puede decirse entonces, que durante la fase de adaptación es el medio de cultivo basal, el que obliga al microorganismo a la producción de sustancias para su viabilidad en el tiempo y la producción de biomoléculas target en las fases posteriores (38) como por ejemplo: (i) iniciando fase Log: Producción de Hormona de Crecimiento humano (RhFH) (39); (ii) durante la fase log: producción de metabolitos tipo Xilanasa en $B$. pumilus (37) o la producción de péptidos de tipo antibiótico como la Iturina A en B. subtilis (40); (iii) Durante la fase tardía de log: producción de
D-ribosa (41) y (iv) durante el final de la fase Log e iniciando Fase Estacionaria: producción de adenosina (42).

La temperatura al igual que las fuentes nutricionales es el factor más determinante del crecimiento bacteriano, dado que proporciona la energía necesaria para la transición del umbral de activación que es requerido en las diferentes reacciones posteriores a la fase de adaptación.

Otras variables del proceso fermentativo son la agitación y la aireación las cuales son determinantes en procesos productivos de surfactina, para el caso de especies como el Bacillus amyloliquefaciens (43).

En el caso del Bacillus cereus, además de sus propiedades como productor de metabolitos, entender su curva de crecimiento, favorecerá el diseño de modelos de pasterización y control de productos en la industria alimentaria para evitar pérdidas económicas por su capacidad de producción de esporas resistentes a altas temperaturas y su facilidad de crecer en alimentos en refrigeración especialmente futas y vegetales $(22,44-47)$.

El conocimiento logrado en este estudio facilitará la estandarización del método de obtención de metabolitos como Fengicina e Iturina A, a partir del B. subtilis y la Xilanasa en B. pumilus, la producción a gran escala y la formulación de productos de interés agrícolas menos nocivos con el ambiente y eficientes como biocontroladores de fitopatógenos como el Fusarium sp.

\section{Agradecimientos}

Al Departamento Administrativo de CT+i Colciencias y a la Universidad Colegio Mayor de Cundinamarca - Facultad de Ciencias de la Salud, programa de Bacteriología y laboratorio Clínico por la financiación de Joven Investigador convocatoria del año 2010. A la docente Judith Huérfano, quien apoyó la elaboración de medios de cultivo para el crecimiento bacteriano objeto de estudio. 


\section{Referencias}

1. Parra NSR. Contexto y perspectiva de la red de suministro: Plantas aromáticas en Colombia. Vol. 33, REVISTA ECONÓMICAS CUC. 2012. p. 135-56.

2. ASOHOFRUCOL [Internet]. [cited 2016 Nov 5]. Available from: http://www.asohofrucol.com.co/bibliotecavirtual.php

3. Laurence MH, Summerell BA, Burgess LW, Liew ECY. Genealogical concordance phylogenetic species recognition in the Fusarium oxysporum species complex. Fungal Biol. 2014;118(4):374-84.

4. McGovern RJ. Management of tomato diseases caused by Fusarium oxysporum. Crop Prot. 2015 Jul;73:78-92.

5. Zakaria L, Leong SK, Latiffah Z, Baharuddin S. Molecular Characterization of Fusarium Oxysporum F. Sp. Cubense of Banana. Am J Appl Sci. 2009;6(7):1301-7.

6. Steinkellner S, Mammerler R, Vierheilig H. Germination of Fusarium oxysporum in root exudates from tomato plants challenged with different Fusarium oxysporum strains. Eur J Plant Pathol. 2008 Nov 3;122(3):395-401.

7. Cao Y, Xu Z, Ling N, Yuan Y, Yang X, Chen L, et al. Isolation and identification of lipopeptides produced by B. subtilis SQR 9 for suppressing Fusarium wilt of cucumber. Sci Hortic (Amsterdam). 2012;135:32-9.

8. Sharma RR, Singh D, Singh R. Biological control of postharvest diseases of fruits and vegetables by microbial antagonists: A review. Biol Control. 2009;50(3):205-21.

9. Baker KF (Kenneth F, Cook RJ. Biological control of plant pathogens. American Phytopathological Society; 1982.

10. Cook RJ, Abel P, Nelson R, De B, Hoffmann N, Rogers S, et al. Biological control and holistic plant-health care in agriculture. Am J Altern Agric. 1988 Jan 30;3(2-3):51.

11. El Arbi A, Rochex A, Chataigné G, Béchet M, Lecouturier $\mathrm{D}$, Arnauld S, et al. The Tunisian oasis ecosystem is a source of antagonistic Bacillus spp. producing diverse antifungal lipopeptides. Res Microbiol. 2016 Jan;167(1):46-57.

12. Ojiambo PS, Scherm H. Biological and application-oriented factors influencing plant disease suppression by biological control: a meta-analytical review. Phytopathology. 2006;96(11):1168-74.

13. Pavlou GC, Vakalounakis DJ. Biological control of root and stem rot of greenhouse cucumber, caused by Fusarium oxysporum f. sp. radicis-cucumerinum, by lettuce soil amendment. Crop Prot. 2005;24(2):135-40.

14. Melnick RL, Zidack NK, Bailey BA, Maximova SN, Guiltinan M, Backman PA. Bacterial endophytes: Bacillus spp. from annual crops as potential biological control agents of black pod rot of cacao. Biol Control. 2008 Jul;46(1):46-56.

15. Nagórska K, Bikowski M, Obuchowski M. Multicellular behaviour and production of a wide variety of toxic substances support usage of Bacillus subtilis as a powerful biocontrol agent. Acta Biochim Pol. 2007;54(3):495-508

16. Leelasuphakul W, Hemmanee P, Chuenchitt S. Growth inhibitory properties of Bacillus subtilis strains and their metabolites against the green mold pathogen (Penicillium digitatum Sacc.) of citrus fruit. Postharvest Biol Technol. 2008 Apr;48(1):113-21.
17. Kaur P, Bhardwaj NK, Sharma J. Process optimization for hyper production of xylanase via statistical methodology from isolated Bacillus pumilus 3GAH using lignocellulosic waste. Biocatal Agric Biotechnol. 2016 Apr;6:159-67.

18. Ongena M, Jacques P. Bacillus lipopeptides: versatile weapons for plant disease biocontrol. Trends Microbiol. 2008 Mar $1 ; 16(3): 115-25$.

19. Liu J, Hagberg I, Novitsky L, Hadj-Moussa H, Avis TJ. Interaction of antimicrobial cyclic lipopeptides from Bacillus subtilis influences their effect on spore germination and membrane permeability in fungal plant pathogens. Fungal Biol. 2014 Nov;118(11):855-61.

20. Latoud C, Peypoux F, Michel G. Action of iturin A, an antifungal antibiotic from Bacillus subtilis, on the yeast Saccharomyces cerevisiae: Modifications of membrane permeability and lipid composition. J Antibiot (Tokyo). 1987;40(11):1588-95.

21. Universidad Pública de Navarra. Cultivo de microorganismos. 2008;1-19.

22. Guérin A, Dargaignaratz C, Broussolle V, Clavel T, Nguyenthe C. Combined effect of anaerobiosis, low $\mathrm{pH}$ and cold temperatures on the growth capacities of psychrotrophic Bacillus cereus. Vol. 59, Food Microbiology. 2016.

23. Dunlap CA, Bowman MJ, Schisler DA. Genomic analysis and secondary metabolite production in Bacillus amyloliquefaciens AS 43.3: A biocontrol antagonist of Fusarium head blight. Biol Control. 2013 Feb;64(2):166-75.

24. Guez JS, Chenikher S, Cassar JP, Jacques P. Setting up and modelling of overflowing fed-batch cultures of Bacillus subtilis for the production and continuous removal of lipopeptides. $J$ Biotechnol. 2007;131(1):67-75.

25. Kiss A, Balikó G, Csorba A, Chuluunbaatar T, Medzihradszky KF, Alföldi L. Cloning and characterization of the DNA region responsible for Megacin A-216 production in Bacillus megaterium 216. J Bacteriol. 2008 Oct;190(19):6448-57.

26. Akpa E, Jacques P, Wathelet B, Paquot M, Fuchs R, Budzikiewicz $\mathrm{H}$, et al. Influence of Culture Conditions on Lipopeptide Production by Bacillus subtilis. Appl Biochem Biotechnol. 2001;91-93(1-9):551-62.

27. Mizumoto S, Shoda M. Medium optimization of antifungal lipopeptide, iturin A, production by Bacillus subtilis in solidstate fermentation by response surface methodology. Appl Microbiol Biotechnol. 2007 Jul 31;76(1):101-8.

28. Fukusaki E, Panbangred W, Shinmyo A, Okada H. The complete nucleotide sequence of the xylanase gene (xynA) of Bacillus pumilus. FEBS Lett. 1984;171(2):197-201.

29. Krätzschmar J, Krause M, Marahiel MA. Gramicidin S biosynthesis operon containing the structural genes grsA and grsB has an open reading frame encoding a protein homologous to fatty acid thioesterases. J Bacteriol. 1989 Oct;171(10):5422-9.

30. Zhao X, Zhou Z, Han Y, Wang Z, Fan J, Xiao H. Isolation and identification of antifungal peptides from Bacillus BH072, a novel bacterium isolated from honey. Microbiol Res. 2013;168(9):598-606.

31. Yaseen Y, Gancel F, Drider D, Béchet M, Jacques P. Influence of promoters on the production of fengycin in Bacillus spp. Res Microbiol. 2016;167(4):272-81. 
32. Zhao Y, Sangare L, Wang Y, Folly YME, Selvaraj JN, Xing F, et al. Complete genome sequence of Bacillus subtilis SG6 antagonistic against Fusarium graminearum. J Biotechnol. 2015 Jan 20;194:10-1.

33. Consuelo L, Leal Msc S, Constanza L, Ramírez Msc C. Evaluación de la congelación para conservación de especies autóctonas bacterianas.

34. Ezziyyani M, Sánchez CP, Requena ME, Rubio L, Castillo MEC. Biocontrol por Streptomyces rochei - ziyani-, de la podredumbre del pimiento ( Capsicum annuum l.) Causada por Phytophthora capsici. An Biol. 2004;0(26):61-8.

35. Dauner M, Storni T, Sauer U, Sauer UWE. Bacillus subtilis Metabolism and Energetics in Carbon-Limited and ExcessCarbon Chemostat Culture Bacillus subtilis Metabolism and Energetics in Carbon-Limited and Excess-Carbon Chemostat Culture. J Bacteriol. 2001;183(24):7308-17.

36. Piedrahíta-Aguirre CA, Alegre RM. Production of lipopeptide iturin a using novel strain Bacillus iso 1 in a packed bed bioreactor. Biocatal Agric Biotechnol. 2014 Apr;3(2):154-8.

37. Kapilan R, Arasaratnam V. Paddy Husk as Support for Solid State Fermentation to Produce Xylanase from Bacillus pumilus. Rice Sci. 2011;18(1):36-45.

38. Öztürk S, Çalık P, Özdamar TH. Fed-Batch Biomolecule Production by Bacillus subtilis: A State of the Art Review. Trends Biotechnol. 2016;34(4):329-45.

39. Şahin B, Öztürk S, Çalık P, Özdamar TH. Feeding strategy design for recombinant human growth hormone production by Bacillus subtilis. Bioprocess Biosyst Eng. 2015 Oct 24;38(10):1855-65.

40. Ye Y, Li Q, Fu G, Yuan G, Miao J, Lin W. Identification of Antifungal Substance (Iturin A2) Produced by Bacillus subtilis B47 and Its Effect on Southern Corn Leaf Blight. J Integr Agric. 2012;11(1):90-9.
41. Park Y-C, Kim S-G, Park K, Lee KH, Seo J-H. Fed-batch production of d-ribose from sugar mixtures by transketolasedeficient Bacillus subtilis SPK1. Appl Microbiol Biotechnol. 2004 Dec 16;66(3):297-302.

42. Chen X, Zhang C, Cheng J, Shi X, Li L, Zhang Z, et al. Enhancement of adenosine production by Bacillus subtilis CGMCC 4484 through metabolic flux analysis and simplified feeding strategies. Bioprocess Biosyst Eng. 2013 Dec 25;36(12):1851-9.

43. Yao S, Zhao S, Lu Z, Gao Y, Lv F, Bie X. Control of agitation and aeration rates in the production of surfactin in foam overflowing fed-batch culture with industrial fermentation. Rev Argent Microbiol. 2015;47(4):344-9.

44. Sadfi N, Chérif M, Hajlaoui MR, Boudabbous A, Bélanger R. Isolation and partial purification of antifungal metabolites produced by Bacillus cereus. Ann Microbiol. 2002;52:323-37.

45. Ramírez LCC, Arévalo GZY, Moreno BVE. Solubilización de fosfatos: una función microbiana importante en el desarrollo vegetal. Nova. 2014; 12(21).

46. Ramírez LCC, Leal LCS, Rodríguez FAE. Determinación de la presencia de bacterias patógenas para el humano en aguas de riego en la cuenca alta de la sabana de Bogotá; DC Colombia. Nova. 2014;12(22).

47. Corrales LC, Romero DMA, Macías JAB, Vargas AMC. Bacterias anaerobias: procesos que realizan y contribuyen a la sostenibilidad de la vida en el planeta. Nova. 2015;13(24):5582. 